\title{
Real-time national GPS networks: Opportunities for atmospheric sensing
}

\author{
Randolph H. Ware ${ }^{1}$, David W. Fulker ${ }^{1}$, Seth A. Stein ${ }^{2}$, David N. Anderson ${ }^{3}$, Susan K. Avery ${ }^{3}$, Richard D. Clark ${ }^{4}$, \\ Kelvin K. Droegemeier ${ }^{5}$, Joachim P. Kuettner ${ }^{1}$, J. Minster ${ }^{6}$, and Soroosh Sorooshian ${ }^{7}$ \\ ${ }^{1}$ University Corporation for Atmospheric Research, Boulder, CO 80307-3000, U.S.A. \\ ${ }^{2}$ Northwestern University, Evanston, IL, U.S.A. \\ ${ }^{3}$ University of Colorado, Boulder, CO, U.S.A. \\ ${ }^{4}$ Millersville University of Pennsylvania, Millersville, PA, U.S.A. \\ ${ }^{5}$ University of Oklahoma, Norman, OK, U.S.A. \\ ${ }^{6}$ University of California at San Diego, La Jolla, CA, U.S.A. \\ ${ }^{7}$ University of Arizona, Tucson, AZ, U.S.A.
}

(Received November 14, 1999; Revised June 13, 2000; Accepted June 13, 2000)

\begin{abstract}
Real-time national Global Positioning System (GPS) networks are being established in a number of countries for atmospheric sensing. UCAR, in collaboration with participating universities, is developing one of these networks in the United States. The network, named "SuomiNet" to honor meteorological satellite pioneer Verner Suomi, is funded by the U.S. National Science Foundation. SuomiNet will exploit the recently-shown ability of groundbased GPS receivers to make thousands of accurate upper and lower atmospheric measurements per day. Phase delays induced in GPS signals by the ionosphere and neutral atmosphere can be measured with high precision simultaneously along up to a dozen GPS ray paths in the field of view. These delays can be converted into total electron content (TEC), and integrated water vapor (if surface pressure data or estimates are available), along each GPS ray path. The resulting continuous, accurate, all-weather, real-time upper and lower atmospheric data create a variety of opportunities for atmospheric research. In this letter we describe SuomiNet, its applications, and the opportunity to coordinate national real-time GPS networks to create a global network with larger scientific and operational potential.
\end{abstract}

\section{Introduction}

SuomiNet will demonstrate the innovative concept of a university-based national geophysical instrument providing real-time atmospheric data for research and education. It will use well established Internet Data Distribution (IDD) software and protocols to coordinate network sensors and distribute its data in real-time (IDD has evolved over more than a decade to provide real-time atmospheric data to university users). Continuous, all-weather, real-time GPS moisture data will help advance university research in mesoscale modeling and data assimilation, severe weather, precipitation, cloud dynamics, regional climate and hydrology. TEC and ionospheric scintillation data derived from GPS signal phase and amplitude will help universities and research institutions address over-arching, fundamental research topics. These topics include the processes that govern the spatial distribution of ionization; the evolution of ionospheric irregularities and scintillation; thermospheric dynamics and its coupling to the ionosphere; and validation, testing and continued development of research models and numerical methods.

\section{Research Applications}

Universities have registered to establish 126 SuomiNet

Copy right (C) The Society of Geomagnetism and Earth, Planetary and Space Sciences (SGEPSS); The Seismological Society of Japan; The Volcanological Society of Japan; The Geodetic Society of Japan; The Japanese Society for Planetary Sciences. sites (Fig. 1). At each SuomiNet site, participating universities will install and operate a standardized system including a dual-frequency GPS receiver, surface meteorological sensors, and a computer connected to the Internet and configured with IDD software. SuomiNet will provide raw GPS and surface meteorological data, tropospheric and ionospheric delays, 2-D water vapor and TEC data to universities in real-time, as illustrated in Fig. 2. University investigators, through independent research programs, could assimilate these data into models to provide real-time 3-D water vapor and electron densities, and to enhance space weather and hydrological cycle modeling. IDD is designed to allow universities to request delivery of specific data sets directly to their computers, as soon as they are available (Domenico et al., 1994).

An IDD characteristic relevant to SuomiNet is that the data streams are accessible at no cost (either for data or software) to any college or university, large or small. The system design also allows any participant to inject additional observations or derived products into the IDD for delivery to other interested members of the network. Coordinated real-time control of GPS and other SuomiNet equipment, such as sampling frequency, data type and format, data latency, and other sensor parameters will be provided via IDD. Thus, SuomiNet will demonstrate the concept of a national geophysical instrument coordinated via Internet. Once demonstrated, this concept has the potential to address many additional research 


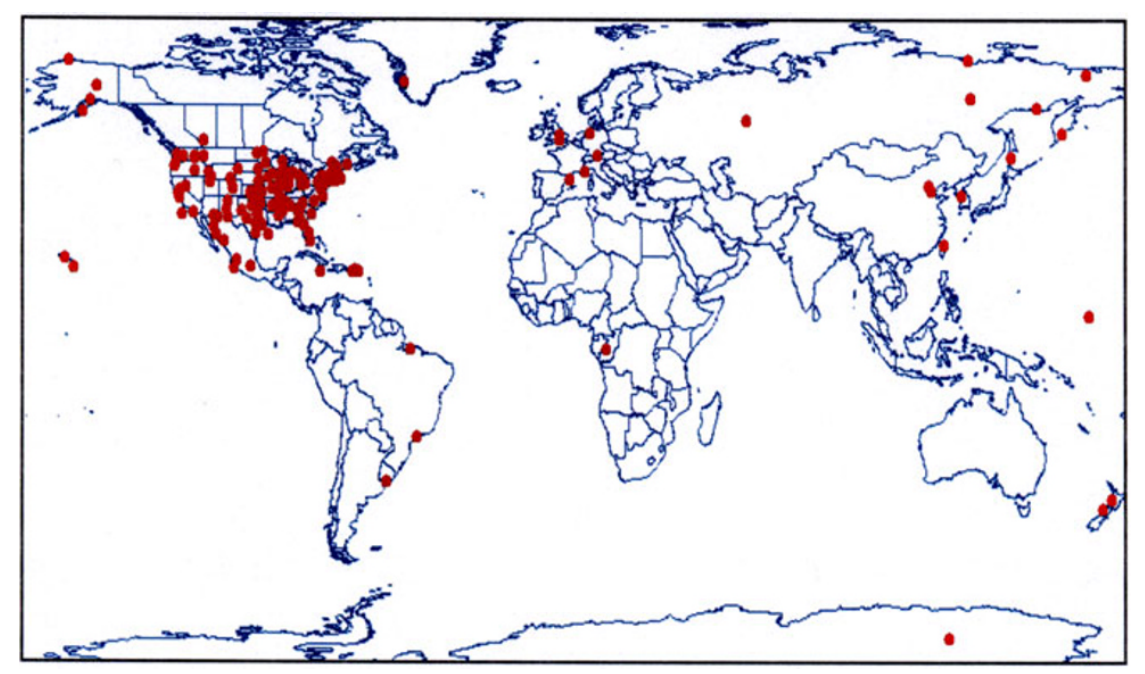

Fig. 1. Universities have registered the indicated site locations for participation in SuomiNet. For prospective participants, information and on-line registration are available via www. unidata.ucar. edu/suominet.

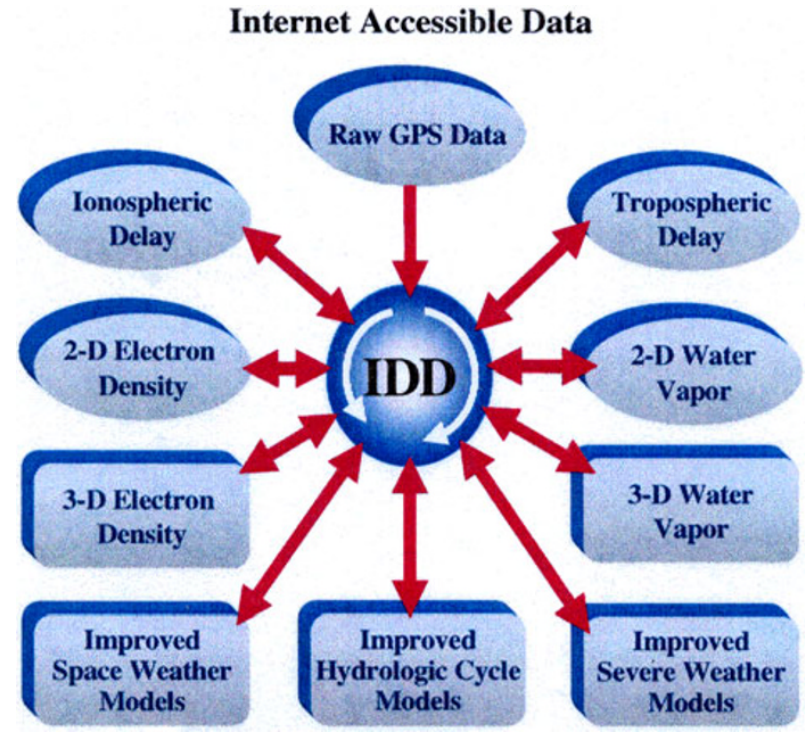

Fig. 2. SuomiNet data and products to be provided to universities in real-time are represented by the oval symbols. Data products that are expected to be derived from SuomiNet data through independent university research programs are represented by rectangular symbols.

and education objectives, as described below.

The feasibility of providing real-time GPS data and products via Internet has already been demonstrated during the past several years using GPS and surface meteorological data from a 50-site network in the south-central U.S. (Rocken et al., 1997). Real-time GPS analysis is based on the zero difference method (Alber et al., 2000). An example of real-time atmospheric water vapor from this network is shown in Fig. 3.

\subsection{Water vapor in atmospheric processes}

Water vapor, the means by which moisture and latent heat are transported, plays a fundamental role in atmospheric processes that act over a wide range of spatial and temporal scales. It is widely recognized that water vapor fields are inadequately defined in global, regional and local weather analysis and forecasting. This inadequacy stems from the sparsity of water vapor observations, combined with the high spatial and temporal variability of water vapor fields (Trenberth and Guillemot, 1996). Traditional water vapor observing systems include radiosondes, surface-based humidity sensors, surface and satellite-based radiometers, and research aircraft. Ground-based GPS sensing of atmospheric water vapor (Bevis et al., 1992; Rocken et al., 1993; Duan et al., 1996) is complementary to these traditional systems, providing autonomous, frequent, economical, and accurate water vapor data that are unaffected by weather conditions or time-of-day.

Water vapor is a greenhouse gas that plays a critical role in the global climate system. This role is not restricted to absorbing and radiating energy from the Sun (Stokes and Schwartz, 1994), but includes the role of water vapor on the formation of clouds and aerosols, and on the chemistry of the lower atmosphere. SuomiNet will provide accurate realtime water vapor data on a regional and continental scale. It also presents an opportunity for international collaboration to establish a global real-time GPS network for atmospheric research.

\subsection{Sensing atmospheric water vapor with GPS}

There are several approaches to GPS sensing of atmospheric water vapor from the ground. The first to be developed uses standard space geodetic techniques (Segall and Davis, 1997) to estimate the 2 to 3 meter zenith phase delay induced in GPS signals by the neutral atmosphere. Residual signal delays to each satellite are mapped as the cosecant of the satellite elevation angle (Niell, 1996), based on the assumption that the atmosphere is azimuthally homogeneous. This gives an average zenith delay, from which the hydrostatic or "dry" component, estimated from surface pressure, is subtracted. PW (precipitable water) is calculated as the product of the zenith delay and a conversion factor (Bevis et al., 1994). The accuracy of GPS sensed PW by this method is better than $2 \mathrm{~mm}$ (Rocken et al., 1997).

Averaging and the assumption of azimuthal symmetry limits the accuracy and spatial resolution of GPS sensed PW. 


\section{Real-Time GPS Sensing of Precipitable Water (PW) 9/15/99 18:00 UT}

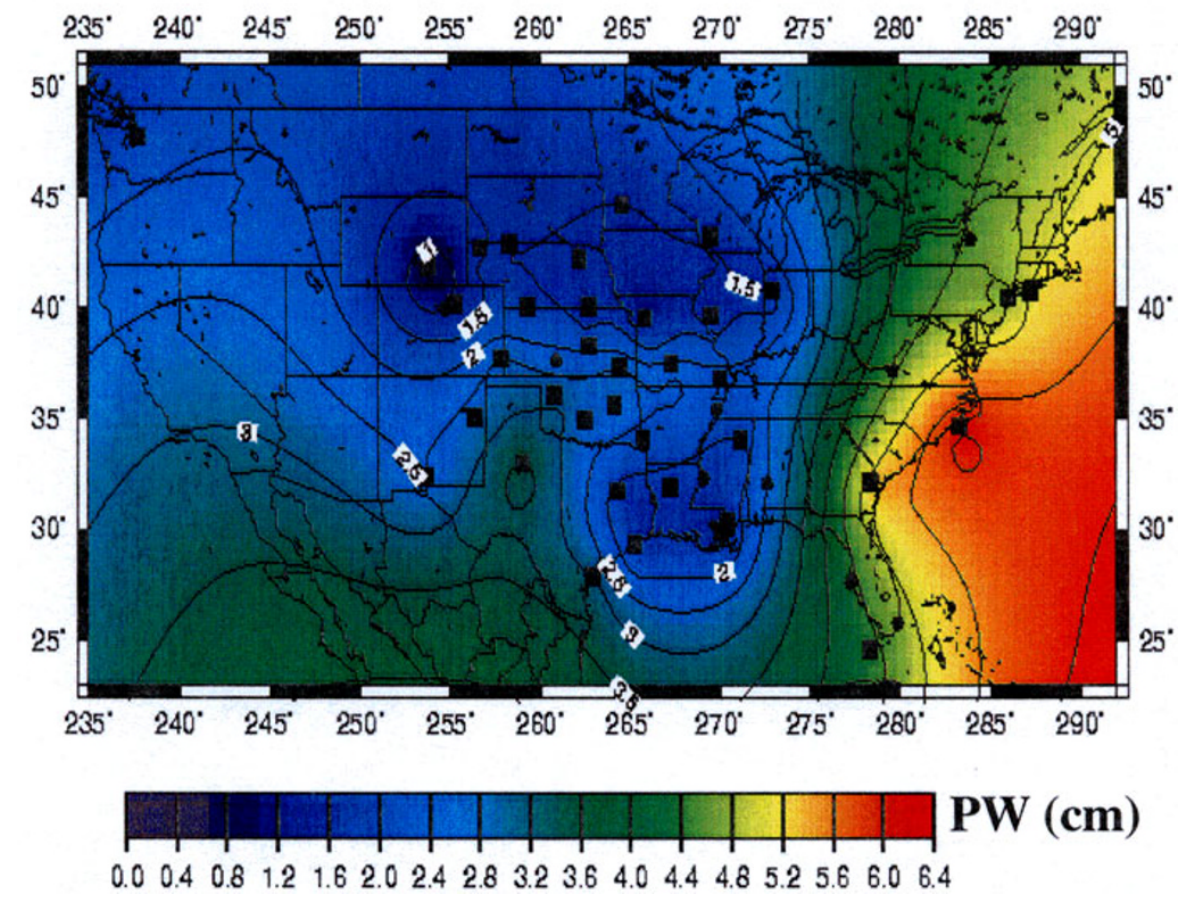

Fig. 3. Precipitable water (PW) estimated from GPS measurements in the south-central U.S., as posted on the Web every 30 minutes (Rocken et al., 1997; www.gst.ucar.edu/gpsrg/realtime.html). Site locations are represented by black squares and dots. Hurricane Floyd made landfall in South Carolina at this time.

Higher spatial resolution can be obtained by solving for the integrated water vapor or "slant water" (SW) along each GPS ray path (Ware et al., 1997). SW is obtained by solving for the total slant delay along each ray path, and then subtracting the dry component of the slant delay. The dry slant delay can be estimated from surface pressure measurements or from three-dimensional numerical weather models (Chen and Herring, 1996).

The increased spatial resolution of SW sensing is based on the ability of commercial GPS receivers to track up to a dozen GPS satellites at any moment in time. The tracking can be continued down to about a half a degree below the horizon as a result of refractive bending. At zero degree elevation, a GPS ray reaches an altitude of $2 \mathrm{~km}$ at a distance of about $200 \mathrm{~km}$ from a ground-based GPS antenna. Comparison of GPS and pointed radiometer data determined GPS sensed SW noise levels at $1.4 \mathrm{~mm}$ rms near 10 degrees elevation angle, decreasing to $0.3 \mathrm{~mm}$ rms near the zenith (Braun et al., 2000). Various experiments demonstrate that GPS sensed SW data can be used to determine atmospheric water vapor structure with high resolution (Hirahara, 2000; Flores et al., 2000; MacDonald and Xie, 2000; MacDonald et al., 2000; Seko et al., 2000).

\subsection{Sensing the ionosphere with GPS}

Hemispheric and global mapping of vertically averaged TEC has been demonstrated using GPS data from the International GPS Service (IGS) network (igscb/ jpl . nasa . gov) including approximately 200 GPS stations distributed worldwide (Zumberge et al., 1997). These two- dimensional horizontal maps are made using a Kalman filter and a mapping function to convert slant to vertical measurements (Ho et al., 1996). More complex modeling of the ionosphere has been demonstrated using IGS data and a stochastic tomographic approach with a two-layer model (Juan et al., 1997). The model characterized low resolution time varying three-dimensional TEC structure on a global scale. A similar approach provides real-time maps of global TEC, plus one and two day predictions via Internet (www. Cx. unibe. ch/ aiub/ionosphere.html). SuomiNet will contribute high resolution TEC data to improve the fidelity of ionospheric mapping, modeling and prediction over the U.S. Combined with data from real-time networks in other countries and from GPS receivers in orbit (Ware et al., 1996), three dimensional ionospheric modeling on a global scale can be achieved (Howe et al., 1998).

\subsection{Additional applications}

Real-time GPS network data can be used for a variety of additional applications, including:

Coastal Meteorology. Estimation of PW (precipitable water) from buoy-based GPS data has been demonstrated (Dodson et al., 1999; Brooks et al., 2000). GPS sensing of water vapor from buoys holds promise for other applications. For example, buoys moored offshore from the west coast of the U.S. could provide data that are valuable for coastal meteorology, and drifting buoys with satellite links could provide water vapor data for mesoscale (and global) modeling research. Buoy-based GPS sensing could also provide TEC data for global ionospheric modeling research, as 
well as ocean current and water temperature data for El Niño, tropical cyclone, and climate related research.

Hydrology. Hydrology is a data-poor science. In particular, atmospheric analyses interpolate and extrapolate radiosonde measurements from coarsely and irregularly spaced land locations, with inadequate spatial and temporal resolution, to represent small-scale hydrological processes (Roads et al., 1994). The availability of distributed, accurate, timely, GPS sensed atmospheric water vapor data on a continental scale is expected to stimulate rapid advancement in hydrology. These data can be assimilated into mesoscale models along with other data for use in estimating four-dimensional water vapor fields, allowing estimation of water vapor flux into watershed regions, and on continental scales.

Climatology. Ground and space based GPS data are sensitive to regional and global climate change (Yuan et al., 1993; Stevens, 1999). Major advantages of GPS data for climatology are all-weather availability, long term stability without calibration, and continuous sampling. Regional climate research will benefit from improved water vapor field definition by GPS sensed PW and SW data. Global climate research will benefit from long term calibration of radiosonde and satellite radiometric water vapor observations with GPS PW data.

Ground Truth for Satellite Radiometry. Microwave and infrared satellite radiometers are widely used as nadir sensors of atmospheric water vapor. These satellite systems provide valuable water vapor measurements over oceans where atmospheric data are otherwise scarce. However, satellite radiometers are less accurate for sensing tropospheric water vapor over land, particularly during cloudy conditions. High resolution four dimensional water vapor fields based on GPS network data could provide ground truth for comparison with satellite sensed water vapor. Potentially, improved understanding of algorithms and methods for satellite radiometer observations over land could result, leading to improved satellite sensing of water vapor over poorly instrumented land areas.

Topographic SAR Corrections. Signal delays induced by atmospheric water vapor can significantly degrade interferometric synthetic aperture radar (SAR) sensitivity to crustal deformation or topography. The high temporal sampling characteristics of GPS network data can be used to complement the high spatial resolution of the interferometric SAR images. The GPS observations can be used to determine the long wavelength atmospheric signal in the interferometric SAR images, and consequently correct these images in deformation studies (Zebker et al., 1997). If there is no surface deformation during the time interval of data acquisitions, SAR imagery can be used to fill spatial gaps in water vapor observations by GPS receivers (Hanssen et al., 1999). In summary, GPS sensed water vapor data could significantly increase the impact of SAR interferometric imaging in solidEarth and atmospheric sciences.

Ionospheric Signatures of Geophysical Events. GPS network data may contain detectable ionospheric gravity wave signals generated by a variety of geophysical and artificial sources. Included are earthquakes; volcanoes; tsunamis; tornadoes and severe storms; sprites, jets and elves; meteors, meteorites and space debris; and rocket launches (Ware et al., 2000). GPS networks can sample at $1 \mathrm{~Hz}, 10 \mathrm{~Hz}$ or higher, allowing detection of ionospheric signals generated by a variety of geophysical events.

Atmospheric Chemistry. Improved estimates of water vapor flux are expected when GPS sensed water vapor data are properly assimilated into meteorological models. Water vapor flux is useful for modeling of dispersion and chemical processes associated with trace gases, pollutants, water vapor, and aerosols. In addition, regional and global GPS networks could be augmented with additional sensors. For example, hydroxyl, ozone, fluorocarbon, carbon monoxide, sulfate, or nitrate sensors could be added. These sensors, coordinated via IDD, could be used for local, regional and continental atmospheric chemistry studies.

Astronomy. On August 27, 1998, an extremely intense gamma ray flare passed through the solar system, rapidly ionizing the exposed part of the Earth's nightside upper atmosphere, producing ionization levels usually found only during daytime (hail.stanford.edu/gammaray.html). This gamma ray flare originated at a faint X-ray star, located in the distant reaches of our galaxy, some 23,000 light years away. Similar events could be easily detected in GPS observations of TEC.

\section{Conclusions}

Real-time national GPS networks for atmospheric sensing are being established or planned in a number of countries around the world. The resulting continuous, accurate, all-weather, real-time GPS networks will provide a major stimulus to mesoscale modeling and data assimilation, severe weather, precipitation, cloud dynamics, regional climate, hydrology, modeling and prediction of severe terrestrial and space weather, detection and forecasting of low latitude ionospheric scintillation activity and geomagnetic storm effects at ionospheric mid-latitudes, and detection of ionospheric effects induced by a variety of geophysical events. Real-time GPS data also have potential applications in coastal meteorology, climatology, satellite radiometry, correction of synthetic aperture radar data for crustal deformation and topography studies, and boundary layer turbulence. It is important that national real-time GPS networks are coordinated to use common data formats and exchange protocols, and that their data are freely exchanged. This will ensure that the scientific and operational potential of real-time GPS networks is fully realized.

\section{References}

Alber, C., R. Ware, C. Rocken, and J. Braun, Obtaining single path phase delays from GPS double differences, Geophys. Res. Lett., 27, 2661-2664, 2000 .

Bevis, M., S. Businger, T. Herring, C. Rocken, R. Anthes, and R. Ware, GPS meteorology: Remote sensing of atmospheric water vapor using the global positioning system, J. Geophys. Res., 97, 15,787-15,801, 1992.

Bevis, M., S. Businger, S. Chiswell, T. Herring, R. Anthes, C. Rocken, and R. Ware, GPS meteorology: Mapping zenith wet delays onto precipitable water, J. Appl. Meteor., 33, 379-386, 1994.

Braun, J., C. Rocken, and R. Ware, Validation of single slant water vapor measurements with GPS, Radio Sci., 2000 (in press).

Brooks, I., D. Rogers, and L. Regier, The Scripps Institution of Oceanography Marine Observatory: A Platform for Real-Time Measurements of the Coastal Ocean and Atmosphere, 16th International Conference on Interactive Information and Processing Systems (IIPS) for Meteorology, Oceanography, and Hydrology, Long Beach, CA, Jan. 9-14, 2000. 
Chen, G. and T. Herring, Effects of atmospheric azimuthal asymmetry on the analysis of space geodetic data, J. Geophys. Res., 102, 20,489-20,502, 1996.

Dodson, A., C. Wu, N. Penna, and H. Baker, GPS Estimation of Atmospheric Water Vapour from a Moving Platform, IUGG99, Birmingham, U.K., July 18-30, 1999.

Domenico, B., S. Bates, and D. Fulker, Unidata Internet Data Distribution (IDD), Proceedings, Tenth International Conference on Interactive Information and Processing Systems for Meteorology, Oceanography and Hydrology, Am. Met. Soc., J15-J20, 1994.

Duan, J., M. Bevis, P. Fang, Y. Bock, S. Chiswell, S. Businger, C. Rocken, F. Solheim, T. Van Hove, R. Ware, S. McClusky, T. Herring, and R. King, GPS meteorology: Direct estimation of the absolute value of precipitable water vapor, J. Appl. Meteor, 35, 830-838, 1996.

Flores, A., G. Ruffini, and A. Rius, 4D tropospheric tomography using GPS slant wet delays, Ann. Geophysicae, 18, 223-234, 2000.

Haines, B. J. and Y. E. Bar-Sever, Monitoring the TOPEX microwave radiometer with GPS: Stability of columnar water vapor measurements, Geophys. Res. Lett., 25, 3563-3566, 1998.

Hanssen, R., T. Weckworth, H. Zebker, and R. Klees, High-resolution water vapor mapping from interferometric radar measurements, Science, 283, 1297-1299, 1999

Hirahara, K., Local GPS tropospheric tomography, Earth Planets Space, 52, this issue, 935-939, 2000.

Ho, C., A. Mannucci, U. Lindqwister, S. Pi, and B. Tsuritani, Global ionosphere perturbations monitored by the worldwide GPS network, Geophys. Res. Lett., 23, 3219-3222, 1996.

Howe, B., K. Runciman, and J. Secan, Tomography of the ionosphere: Four-dimensional simulations, Radio Sci., 33, 109-128, 1998.

Juan, J. M., A. Rius, M. Hernandes-Pajares, and J. Sanz, A two-layer model of the ionosphere using Global Positioning System data, Geophys. Res. Lett., 24, 393-396, 1997.

MacDonald, A. and Y. Xie, On the Use of Slant Observations from GPS to Diagnose Three Dimensional Water Vapor Using 3DVAR, Proc. 4th Integrated Observing Systems Symp. (Amer. Met. Soc.), Long Beach CA, 62-73, 2000.

MacDonald, A., Y. Xie, and R. Ware, Diagnosis of three dimensional water vapor using slant observations from a GPS network, Bull. Am. Meteor. Soc., 2000 (in preparation)

Niell, A., Global mapping functions for the atmosphere delay at radio wavelengths, J. Geophys. Res., 101, 3227-3246, 1996.

Roads, J., S.-C. Chen, A. Guetter, and K. Georgakakos, Large-scale aspects of the united states hydrological cycle, Bull. Am. Meteor. Soc., 75, 15891610,1994
Rocken, C., R. Ware, T. Van Hove, F. Solheim, C. Alber, and J. Johnson, Sensing atmospheric water vapor with the global positioning system, Geophys. Res. Lett., 20, 2631-2634, 1993.

Rocken, C., T. Van Hove, and R. Ware, Near real-time sensing of atmospheric water vapor, Geophys. Res. Lett., 24, 3221-3224, 1997.

Seko, H., H. Nakamura, T. Kato, and S. Shimada, Estimation of three dimensional distribution of moisture based on GPS precipitable water in meso-scale system in baiu season, Earth Planets Space, 52, this issue, 927-933, 2000.

Segall, P. and J. Davis, GPS applications for geodynamics and earthquake studies, Annu. Rev. Earth Planet. Sci., 25, 301-336, 1997.

Stevens, M., Optimal climate signal detection in four dimensions, J. Geophys. Res., 104, 4089-4099, 1999.

Stokes, G. and S. Schwartz, The Atmospheric Radiation Measurement (ARM) program: Programmatic background and design of the cloud and radiation test bed, Bull. Am. Meteor. Soc., 119, 153-186, 1994.

Trenberth, K. and C. Guillemot, Evaluation of the Atmospheric Moisture and Hydrological Cycle in the NCEP Reanalyses, NCAR Technical Note TN-430, December, 1996.

Ware, R., M. Exner, D. Feng, M. Gorbunov, K. Hardy, B. Herman, H. K. Kuo, T. Meehan, W. Melbourne, C. Rocken, W. Schreiner, S. Sokolovskiy, F. Solheim, X. Zou, R. Anthes, S. Businger, and K. Trenberth, GPS sounding the atmosphere from low Earth orbit, preliminary results, Bull. Am. Meteor. Soc., 77, 19-40, 1996.

Ware, R., C. Alber, C. Rocken, and F. Solheim, Sensing integrated water vapor along GPS ray paths, Geophys. Res. Lett., 24, 417-420, 1997.

Ware, R., D. Fulker, S. Stein, D. Anderson, S. Avery, R. Clark, K Droegemeier, J. Kuettner, J. Minster, and S. Sorooshian, SuomiNet: A real-time national GPS network for atmospheric research and education, Bull. Am. Meteor. Soc., 81, 677-694, 2000.

Yuan, L., R. Anthes, R. Ware, C. Rocken, W. Bonner, M. Bevis, and S Businger, Sensing climate change using the global positioning system, $J$. Geophys. Res., 98, 14,925-14,937, 1993.

Zebker, H., P. Rosen, and S. Hensley, Atmospheric effects in interferometric synthetic radar surface deformation and topographic maps, J. Geophys. Res., 102, 7547-7563, 1997.

Zumberge, J., D. Fulton, and R. Neilan, editors, International GPS Service 1996 Annual Report, IGS Central Bureau, Jet Propulsion Laboratory, Pasadena, CA, 1997.

R. H. Ware (e-mail: ware@ucar.edu), D. W. Fulker, S. A. Stein, D. N. Anderson, S. K. Avery, R. D. Clark, K. K. Droegemeier, J. P. Kuettner, J. Minster, and S. Sorooshian 